\title{
NATURAL ANTHRAQUINONEFROM THE BARK OF Cinchona officinalis $\mathbf{L}$.
}

\author{
Muhamad Insanu*, Syaikhul Aziz, Irda Fidrianny, Rika Hartati, \\ Elfahmi, Sukrasno and Komar Ruslan Wirasutisna \\ ${ }^{1}$ Pharmaceutical Biology Research Group, School of Pharmacy, InstitutTeknologi Bandung, \\ Jl Ganesha no 10, Bandung 40132, West Java, Indonesia \\ *E-mail:insanu@fa.itb.ac.id
}

\begin{abstract}
Cinchona officinalis is known as the source of alkaloid compounds. Almost 7-12\% of alkaloids were contained in its bark. Not many studies reported other chemical compounds in it. This research aimed to isolate non-alkaloid compounds in the $C$. officinalis bark. It was extracted by maceration using n-hexane, ethyl acetate, and ethanol. The alkaloidal fraction was separated from ethylacetate extract based on acid-base reaction. The fractions were continued to the next step of fractionations using vacuum liquid chromatography (VLC) and radial chromatography to yield compound 1. Characterizations of compound 1 were done by spectroscopic methods (UV, IR, ESI-MS, NMR $\left({ }^{1} \mathrm{H}-\right.$, ${ }^{13} \mathrm{C}$-, HSQC, and $\left.\mathrm{HMBC}\right)$ ). The maximum wavelengths of compound 1 were 278 and $430 \mathrm{~nm} .{ }^{1} \mathrm{H}-$ dan ${ }^{13} \mathrm{C}-\mathrm{NMR}$ data showed that compound $\mathbf{1}$ consisted of ten hydrogens and fifteen carbons. ESI-MS showed that the molecular weight was 285.96. It was predicted as 1,3,8-trihydroxy-2-methoxy-9,10-anthraquinone. It was firstly isolated from the ethyl acetate extract of C.officinalis bark.
\end{abstract}

Keywords: Anthraquinone, Cinchona officinalis, Isolation.

@ RASĀYAN. All rights reserved

\section{INTRODUCTION}

Cinchona, locally familiar as kina, related to the Rubiaceae family. This genus originated from South America in a particular center of diversity lying along the Andes Mountain and widely distributed to the warmer and tropical climate, such as Indonesia ${ }^{1}$. Cinchona has considerable pharmacological importance. Mainly due to their alkaloids, they were known as a remedy for malaria.

Furthermore, their alkaloids showed antibacterial, antiarrhythmic, antipyretic, human platelet aggregation inhibition and decreasing the excitability of motor endplate. They were found to be active as a local anesthetic, cardiovascular, stimulant, and minor used for the treatment of ophthalmia and internal hemorrhoids ${ }^{2,3}$.Cinchona bark contained approximately 7-12\% alkaloids ${ }^{3}$ which were quinine, quinidine, cinchonine, and cinchonidine. All of them were classified as quinoline alkaloids. Their first isolation was done in 1817 by Pelletier and Caventou ${ }^{4}$. In the previous research, we have already published $\beta$-sitosterol and sitostenone isolated from acetone extract of Cinchona bark ${ }^{5}$. Thus we will report the isolation and structure elucidation of anthraquinone from ethyl acetate extract of Cinchona bark.

\section{EXPERIMENTAL}

\section{General experimental procedures}

The ${ }^{1} \mathrm{H},{ }^{13} \mathrm{C}$, and 2D-NMR data were obtained by Agilent ${ }^{\circledR}$ series, operating at 500 and $125 \mathrm{MHz}$, TMS was used as an internal reference. Mass spectrum was obtained by ESI-MS Bruker ${ }^{\circledR}$ series. IR spectrum was obtained by Jasco ${ }^{\circledR}$ FT/IR 4200. UV-VIS (Ultraviolet-Visible) spectra were recorded by HewlettPackard $^{\circledR}$ 8453. Vacuum Liquid Chromatography (VLC) was performed using silica gel $60 \mathrm{H} \mathrm{Merck}^{\circledR}$. Radial chromatography was accomplished usingChromatotron ${ }^{\circledR}$ (model 7924T) with silica gel $60\left(\mathrm{GF}_{254}\right.$ Merck $^{\circledR}$ ) as the stationary phase. Thin Layer Chromatography (TLC) was carried out on pre-coated silica gel $60 \mathrm{~F}_{254} \mathrm{Merck}^{\circledR}$ and visualized under UV at $\lambda 254 \mathrm{~nm}, 366 \mathrm{~nm}$ and by spraying with $10 \%(\mathrm{v} / \mathrm{v}) \mathrm{H}_{2} \mathrm{SO}_{4}$ in methanol solution.

Rasayan J. Chem., 12(2), 519-522(2019)

http://dx.doi.org/10.31788/RJC.2019.1221831

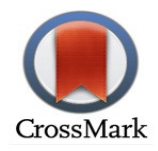




\section{Plant material}

The dried bark of $C$. officinalis L. (Rubiaceae) "clone QRC 281", was obtained from Research Institute for Tea and Cinchona, West Java, Indonesia, in May 2012.It was authenticated by herbarium Bandungense, School of Life Science and Technology, Institut Teknologi Bandung.The voucher specimen was deposited under reference number 010512 in Pharmacognosy Laboratory, School of Pharmacy, Institut Teknologi Bandung.

\section{Extraction and Isolation}

The dried and finely powdered barks $(3 \mathrm{~kg})$ were extracted by maceration at room temperature with nhexane, ethylacetate, and methanol ${ }^{6}(3 \mathrm{x} 5 \mathrm{~L})$. Liquid extracts were concentrated under reduced pressure. The alkaloidal fractions were separated from ethyl acetate extract using acid-base method ${ }^{7}$. The ethyl acetate extract-free alkaloid (13 g), was fractionated by VLC using gradient elution (n-hexane - ethyl acetate-methanol $)^{8}$ to give five significant fractions (A-E). Fraction $\mathrm{C}$ was sub-fractionated by radial chromatography using n-hexane - ethyl acetate $(9: 1.5, \mathrm{v} / \mathrm{v})$ to give eight fractions (C1-C8). Fraction C7 was continued to radial chromatography using n-hexane - ethyl acetate $(7: 4, \mathrm{v} / \mathrm{v})$.

\section{1,3,8-trihydroxy-2-methoxy-9,10-anthraquinone}

Orange amorphous powder, UV $(\mathrm{MeOH}) \lambda_{\max }(\mathrm{nm}): 278,430 \mathrm{~nm}$. IR(KBr) $v_{\max }\left(\mathrm{cm}^{-1}\right): 3340,2923,2854$, 1735, 1619, 1461, 1091, 1180. ESI-MS : $284.96(\mathrm{M}-\mathrm{H})^{-}$(calculated for $\mathrm{C}_{15} \mathrm{H}_{10} \mathrm{O}_{6} ; \mathrm{C} 62.94 ; \mathrm{H} 3.52 ; \mathrm{O}$ 33.54). ${ }^{1} \mathrm{H}$ - and ${ }^{13} \mathrm{C}$ - NMR spectrometer $: \delta$ in ppm rel to TMS, $J$ in Hz (Figure-1 and Table-1). HSQC and HMBC was represented in Table-2.

\section{RESULTS AND DISCUSSION}

Compound 1 isolated from ethyl acetate extract of $C$. officinalis L. bark, was orange amorphous powder. The UV-VIS spectra $(\mathrm{MeOH})$ showed the maximum absorptions at $\lambda 273$ and $430 \mathrm{~nm}$. IR bands at 3340 $\mathrm{cm}^{-1}, 1735 \mathrm{~cm}^{-1}, 1619 \mathrm{~cm}^{-1}$ represented hydroxyl group $(-\mathrm{OH})$, carbonyl group $(\mathrm{C}=\mathrm{O})$ and unsaturated aromatic. The ESI-MS displayed $[\mathrm{M}-\mathrm{H}]^{-}$peak at 284.96 suggesting molecular formula $\mathrm{C}_{15} \mathrm{H}_{10} \mathrm{O}_{6}$ and indicated the presence of eleven double-bond equivalents, eight of them were assumed to be two benzene rings, one additional ring, and two carbonyl groups. The ${ }^{1} \mathrm{H}$-NMR signals were ranged from $\delta(\mathrm{H}) 7.20$ to 7.70 indicated aromatic structure. They had coupling constants that were closely related, $(1 \mathrm{H}, \mathrm{d}, J=8.4$ $\mathrm{Hz})$ and $(1 \mathrm{H}, \mathrm{d}, J=7.4 \mathrm{~Hz})$, those indicated the presence of two protons at the ortho position of the benzene ring. A doublet-doublet aromatic proton at $\delta(\mathrm{H}) 7.57(1 \mathrm{H}$, dd) indicated the presence of one proton which had two neighbor protons while a singlet aromatic proton at $\delta(\mathrm{H}) 7.29(1 \mathrm{H}$, s) suggested that it had no neighbor. The singlet signal at $\delta(\mathrm{H}) 3.96$ indicated a methoxy group with three protons.

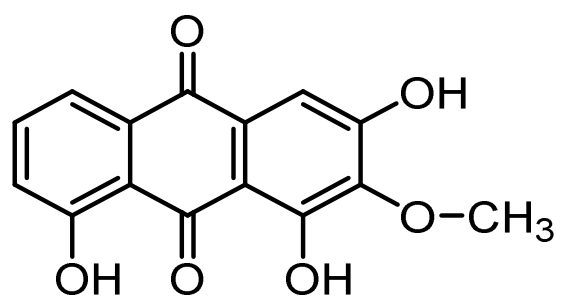

Fig.-1: Structure of Compound 1

The ${ }^{13} \mathrm{C}-\mathrm{NMR}$ spectra showed the presence of 15 atom carbons. The DEPT-HSQC spectra showed that compound 1 contained one methoxy, four methines, and ten quaternary carbons, therefore, an anthraquinone with four substitutes was deducted. The signals at $\delta(C) 181.9$ and 191.6 were attributed to carbonyl groups while $\delta(\mathrm{C}) 60.8$ was associated with the methoxy group. The exact substitutes were also confirmed by HMBC spectra (Fig.-2). There were correlations between $\delta(\mathrm{H}) 3.96(3 \mathrm{H}, \mathrm{s})$ and $\mathrm{C}-2 \delta(\mathrm{C})$ 139.9). Those indicated that the position of the methoxy group was located at C-2. The correspondent between an aromatic proton at $\delta(\mathrm{H}) 7.29(1 \mathrm{H}, \mathrm{s})$ and three aromatic carbons at $\delta(\mathrm{C}) \quad 139.9(\mathrm{C}-2), 181.9$ 
(C-9) and 110.7 (C-9a) showed that the proton was placed at C-4. The interaction between an aromatic proton at $\delta(\mathrm{H}) 7.20(1 \mathrm{H}, \mathrm{d}, J=8.4 \mathrm{~Hz})$ and two aromatic carbons at $\delta(\mathrm{C}) 119.9(\mathrm{C}-8)$ and $116.0(\mathrm{C}-10 \mathrm{a})$ determined that the proton was positioned at C-6. The correlation between an aromatic proton at $\delta(\mathrm{C})$ $7.57(1 \mathrm{H}, \mathrm{dd})$ and two aromatic carbons at $\delta \mathrm{C} 162.0(\mathrm{C}-8)$ and $133.5(\mathrm{C}-8 \mathrm{a})$ indicated that the proton was located at C-7. The correlation between an aromatic proton at $\delta \mathrm{H} 7.70(1 \mathrm{H}, \mathrm{d}, J=7.4 \mathrm{~Hz})$ and three aromatic carbons at $\delta(\mathrm{C}) 124.5(\mathrm{C}-6), 181.9(\mathrm{C}-9)$ and $116.0(\mathrm{C}-10 \mathrm{a})$ showed that the proton was placed at C-5 (Table-1).

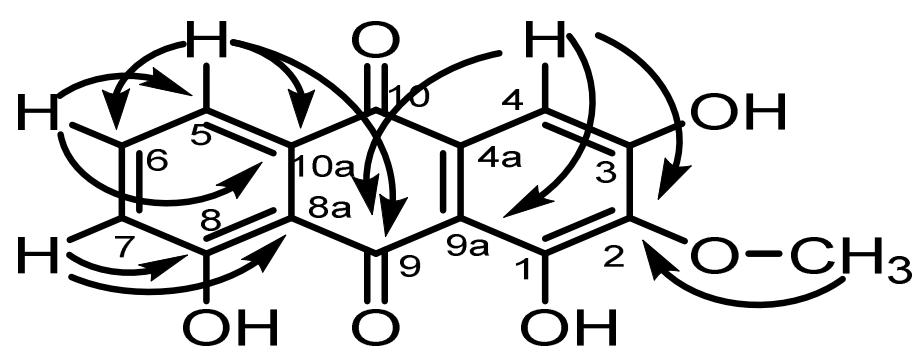

Fig.-2: HMBC Correlation of Compound 1

Based on this data, we suggested that compound 1 was 1,3,8-trihydroxy-2-methoxy-9,10-anthraquinone (Fig.-1). According to our knowledge, it was previously isolated from callus cultures of Cinchona ledgeriana and suspension cultures of Cinchona robusta ${ }^{9-11}$. It was also isolated from the root of Morinda citrifolia which possessed antiosteoporotic. Cinchona and Morinda genus were both classified as Rubiaceae family ${ }^{12}$. Therefore, we courageously claim that 1,3,8-trihydroxy-2-methoxy-9,10anthraquinone is the firstly isolated from the bark of $C$. officinalis $\mathrm{L}$.

Table-1: ${ }^{1} \mathrm{H}(500 \mathrm{MHz}),{ }^{13} \mathrm{C}(125 \mathrm{MHz})$, and 2D-NMR Data $\left(\mathrm{CDCl}_{3}\right)$ of compound 1

\begin{tabular}{|c|c|c|c|}
\hline Position & $\delta \mathrm{C}(\mathrm{ppm})$ & $\delta \mathrm{H}(\mathrm{ppm})$ & HMBC \\
\hline 1 & 157.3 & - & \\
\hline 2 & 139.9 & - & \\
\hline $2-\mathrm{OCH}_{3}$ & 60.8 & $3.96, \mathrm{~s}$ & $\mathrm{C}(2)$ \\
\hline 3 & 129.6 & - & \\
\hline 4 & 109.9 & $7.29, \mathrm{~s}$ & $\mathrm{C}(2), \mathrm{C}(9 \mathrm{a}), \mathrm{C}(9)$ \\
\hline $4 \mathrm{a}$ & 114.0 & - & \\
\hline 5 & 119.9 & $7.70, d, 7.4$ & $\mathrm{C}(6), \mathrm{C}(10 \mathrm{a}), \mathrm{C}(9)$ \\
\hline 6 & 124.5 & $7.20, d, 8.4$ & $\mathrm{C}(10 \mathrm{a}), \mathrm{C}(5)$ \\
\hline 7 & 136.6 & $7.57, \mathrm{dd}, 8.2,7.7$ & $\mathrm{C}(8), \mathrm{C}(8 \mathrm{a})$ \\
\hline 8 & 162.0 & - & - \\
\hline $8 \mathrm{a}$ & 133.5 & - & \\
\hline 9 & 181.9 & - & \\
\hline $9 \mathrm{a}$ & 110.7 & - & \\
\hline 10 & 191.6 & - & \\
\hline $10 \mathrm{a}$ & 116.0 & - & \\
\hline
\end{tabular}

CONCLUSION

Compound 1 was 1,3,8-trihydroxy-2-methoxy-9,10-anthraquinone.

\section{ACKNOWLEDGMENT}

This work was supported by the IMHERE research project from General Directorate of Higher Education, Ministry of Education and Culture of Indonesia.

\section{REFERENCES}

1. L.S.D. Padua, N. Bunyapraphatsara, R.H.M.J. Lemmens. Plant Resources of South-East Asia. Backhuys Publisher Leiden, (1999)

2. S. Sangeetha, N. Manjunatha, M.K. Samanta, M. Malik, Int. J. Biopharmaceutics, 2, 1(2011) 
RASĀYAN J. Chem.

Vol. 12 | No. 2 |519 - 522| April - June | 2019

3. D.V. McCalley, J. Chromatogr. A, 967, 1(2002), DOI:10.1016/S0021-9673(01)01557-6

4. S. Maehara, P. Simanjuntak, C. Kitamura, K. Ohashi, H. Shibuya, Chem. Pharm. Bull., 59, 1073(2011), DOI: $10.1248 / \mathrm{cpb} .59 .1073$

5. S. Aziz, K.R. Wirasutisna, Elfahmi, Sukrasno, Ind. J. Nat. Prod., 8, 221(2013)

6. M. Adfa, A. J. Kusnanda, F. Livandri, R. Rahmad, W. Darwis, M. Efdi, et al., Rasayan J. Chem., 10, 153(2017), DOI: 10.7324/RJC.2017.1011590

7. W.P. Jones, A.D. Kinghorn. Extraction of Plant Secondary Metabolites. In: Sarker SD, Latif Z, Gray AI, editors. Natural Products Isolation. 2. Humana Press.New Jersey p. 323-51 (2006)

8. P. Sugita, S. Arya, A. Ilmiawati, B. Arifin, Rasayan J. Chem., 10, 707(2017), DOI:10.7324/RJC.2017.1031766

9. J. Schripsema, A. Ramos-Valdivia, R. Verpoorte, Phytochemistry, 51, 55(1999), DOI: 10.1016/S0031-9422(98)00470-1

10. J. Schripsema, D. Dagnino, Phytochemistry, 42, 177(1996), DOI: 10.1016/0031-9422(95)00885-3

11. R. Wijnsma, R. Verpoorte, T. Mulder-Krieger, A.B. Svendsen, Phytochemistry, 23, 2307(1984), DOI: 10.1016/S0031-9422(00)80541-5

12. Y.B. Wu, C.J. Zheng, L.P. Qin, L.N. Sun, T. Han, L. Jiao, et al., Molecules, 14, 573(2009), DOI:10.3390/molecules 14010573

[RJC-1831/2018] 